\title{
Synthesis of 2,5-Diarylated Thiophene 1,1-Dioxides
}

\section{Key words}

tin

palladium

thiophene dioxides

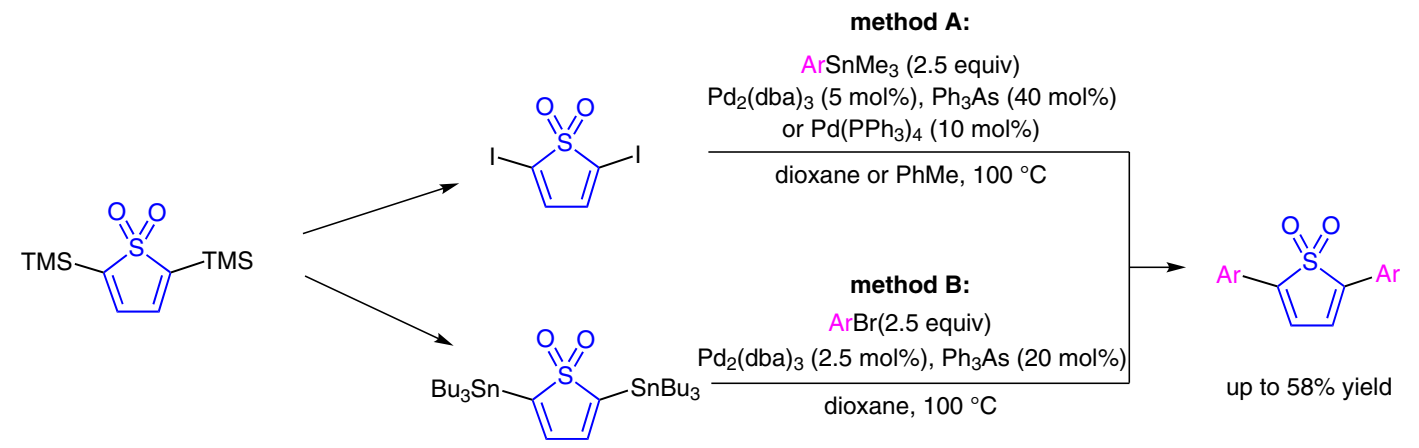

$\mathrm{Ar}=\mathrm{Ph}, 4-\mathrm{MeOC}_{6} \mathrm{H}_{4}, 4-\mathrm{F}_{3} \mathrm{CC}_{6} \mathrm{H}_{4}, 4-\mathrm{NCC}_{6} \mathrm{H}_{4}, 4-\mathrm{O}_{2} \mathrm{NC}_{6} \mathrm{H}_{4}$, 2-thienyl, 2-furyl, 5-thiazolyl

Selected examples:

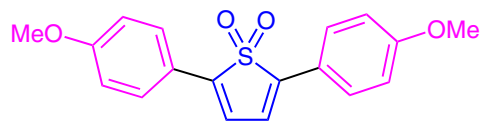

$27 \%$ yield $(\operatorname{method} A)$

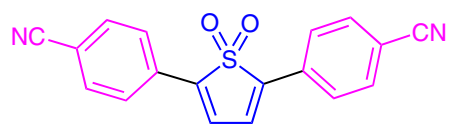

$44 \%$ yield (method B)

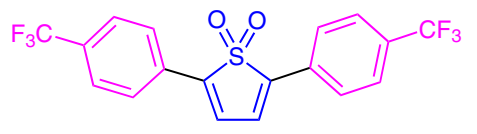

$28 \%$ yield (method B)

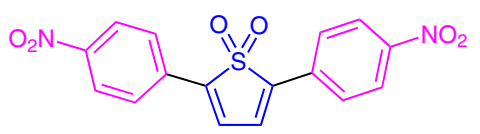

$58 \%$ yield (method B)

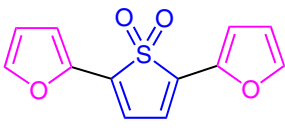

$52 \%$ yield $(\operatorname{method} A)$

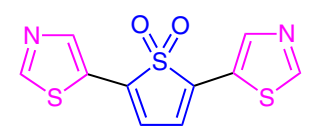

$20 \%$ yield (method B)
Significance: The authors disclose the palladium-catalyzed diarylation of distannylated thiophene 1,1-dioxide (electron-poor aryl coupling partners) and diiodo thiophene 1,1-dioxide (electron-rich aryl coupling partners) by Stille crosscoupling reactions to synthesize various 2,5bis(aryl)thiophene 1,1-dioxides in moderate yields. Furthermore, the electrochemical and photophysical properties of these diarylated thiophene dioxides were investigated using cyclic voltammetry and fluorescence spectroscopy.

SYNFACTS Contributors: Paul Knochel, Nadja M. Bar

Synfacts 2014, 10(1), 0075 Published online: 13.12.2013 DOI: 10.1055/s-0033-1340375; Reg-No.: P16513SF
Comment: The corresponding distannylated thiophene 1,1-dioxides are obtained by treatment of 2,5-bis(trimethylsilyl)thiophene 1,1-dioxide with tetrabutylammonium fluoride (TBAF) and bis(tributyltin) oxide. A wide range of these diarylated thiophene dioxides show significant quantum yields, and their appropriate reduction and oxidation potentials may easily be tuned by the use of electron-donating and -withdrawing aryl groups. 